Фихте», где он заявляет, что считает «наукоучение Фихте совершенно несостоятельной системой» [3, с. 263].

$$
* * *
$$

1. Калинников Л.А. О необходимости переоценки неокантианства в свете современной интерпретации системы И. Канта / Неокантианство немецкое и русское: между теорией познания и критикой культуры. - М. $-2010 .-$ C. 56-66.

2. Перов Ю.В. Кант о способности суждения в контексте природы и свободы, сущего и должного / Ю.В. Перов, К.А. Сергеев, Я.А. Слинин. Очерки истории классического немецкого идеализма. - СПб: Наука. - 2000. - С. 207-267.

3. Кант И. Заявление по поводу Наукоучения Фихте / Собрание сочинений. В 8 т. Т. 8. - М., 1994. - С. 263-264.

\title{
Ушаков Е.В. \\ Моральные аспекты качества жизни как базисного понятия современной медицины
}

Российская академия народного хозяйства и государственной службы при Президенте РФ (Северо-западньй институт управления) (Россия, Санкт-Петербург)

doi: 10.18411/trnio-09-2021-105

\section{Аннотация}

Статья посвящена концепциям качества жизни в современной биоэтике. Качество жизни является одной из ключевых категорий медицины. Имеются расхождения в интерпретации качества жизни в медицинской науке и практике. Обсуждаются две концепции, связанные с данным понятием. Делается вывод о безусловной значимости качества жизни для медицинской сферы и необходимости дальнейшего обсуждения и развития этого понятия.

Ключевые слова: качество жизни, биомедицина, биомедицинская этика, философия медицины, моральные основания медицины, медицинские вмешательства.

\section{Abstract}

The article is devoted to the concepts of the quality of life in modern bioethics. Quality of life is one of the key categories of medicine. There are discrepancies in the interpretation of the quality of life in medical science and practice. Two concepts related to this concept are discussed. The conclusion is made about the unconditional importance of the quality of life for the medical sphere and the need for further discussion and development of this concept.

Keywords: quality of life, biomedicine, biomedical ethics, philosophy of medicine, moral foundations of medicine, medical interventions.

Медицинские вмешательства оказывают на человека комплексное воздействие. Они влияют не только на физиологическое состояние организма (что оценивается с помощью лабораторно-клинических показателей), но и на общее состояние и самочувствие пациента, его работоспособность, настроение и т.п. Суммарное влияние на пациента может быть как положительным, так и отрицательным. Например, агрессивное лечение может сопровождаться такими серьезными побочными эффектами, что в известном смысле может оказаться хуже, чем само заболевание.

В начальный период успехов современных медицинских технологий (примерно в 50 60-е годы XX в.) медицинское сообщество было увлечено сугубо техническими достоинствами новых медицинских методов. Однако постепенно ситуация стала изменяться в связи с растущим осознанием необходимости дополнить систему взглядов о пользе медицинского вмешательства более широкой картиной, в том числе учитывающей точку зрения самого больного.

Официальное определение ВОЗ гласит, что качество жизни - это «восприятие индивидами их положения в жизни в контексте культуры и систем ценностей, в которых они 
живут, и в соответствии с их собственными целями, ожиданиями, стандартами и заботами» $[1]$.

Качество жизни - интегральный показатель, отражающий совокупное влияние массы факторов, связанных со здоровьем, на общее восприятие пациентом своей жизненной ситуации. К этим факторам относятся такие, как уровень физического благополучия, ощущение себя здоровым или больным, самостоятельным или же зависимым от помощи, а также способность выполнять профессиональные обязанности, поддерживать семейные и социальные связи.

Проблема качества жизни пришла в медицинскую сферу из социальных наук, где она сформировалась как особое поле исследований, охватываемых обширной группой дисциплин и направлений: экономикой, социологией, демографией, политологией, экологией, психологией и другими. В основании темы качества жизни лежат также глубокие философские обсуждения того, что такое «благополучная» или «совершенная» жизнь, уходящие корнями еще в философские учения античности.

В медицинской сфере эта проблема отразилась, прежде всего, в виде проблемы «качества жизни, связанного со здоровьем». Интерес медицинского сообщества к качеству жизни в связи со здоровьем и лечением возник в 70-е годы, и далее усиливался в возрастающей мере в 80-е и 90-е годы. В 1999 г. появилась первая монография на эту тему и в отечественной литературе [2]. На сегодняшний день проблема оценки качества жизни, связанного со здоровьем, стала чрезвычайно обширной и самостоятельной областью исследований в медицинских науках.

Роль понятия качества жизни в медицинской сфере сегодня чрезвычайно важна. Это можно рассматривать как отражение все более растущего внимания медиков и общественности к широкому гуманитарному контексту, в котором происходит предоставление медицинской помощи. Фундаментальное значение концепции качества жизни состоит в том, что она позволяет конкретизировать понятие «благо для пациента» и сами цели медицинской помощи в современных условиях.

Так, учет качества жизни чрезвычайно важен при долгосрочной помощи, а также при неизлечимых заболеваниях и состояниях. Более того, в этих ситуациях обеспечение максимально высокого качества жизни оказывается, фактически, единственной достижимой целью медицинской помощи. Медицинская помощь должна быть предоставлена при любых страданиях, что, соответственно, приводит к необходимости уметь ставить цели и оценивать эффективность помощи и в указанных обстоятельствах.

С расширением возможностей современной медицины ее основная задача действовать во благо больного - стала требовать переосмысления и уточнения. Как понимать «благо для пациента» в нынешних условиях? Одной из фундаментальных проблем биомедицинской этики оказалась проблема жизни как ценности. В мировой литературе сформировались две точки зрения по этому поводу. Одну можно назвать этикой «сакральности жизни» или «жизни как высшей ценности» (sanctity of life), вторую - этикой «качественной жизни» (quality of life). Надо отметить, что эти концепции носят в значительной мере условный характер, они как бы представляют собой крайние точки на карте запутанных биоэтических дискуссий.

Первая концепция признает любую человеческую жизнь высшей ценностью. Соответственно, задачей медицины в этом ракурсе является сохранение и поддержание жизни любого человеческого организма. В биоэтической литературе есть такое понятие, как «медицинский витализм». Это обозначение такой предельной точки зрения, которая гласит, что необходимо поддерживать любую жизнь, не считаясь ни с какими затратами (конечно, далеко не все сторонники этики сакральности жизни придерживаются таких крайних взглядов). Например, с этой точки зрения нужно до бесконечности поддерживать искусственными средствами жизнь человека, находящегося в т.н. «вегетативном состоянии», без какой-либо надежды вернуть его в сознание. 
Согласно второй концепции, подлинно человеческая жизнь должна обладать определенными «качествами», поэтому далеко не все состояния организменной жизни надо поддерживать. Предполагается, что должны существовать какие-то критерии, посредством которых можно решить, где следует оказывать медицинскую помощь, а где ее можно прекратить (или вообще не начинать).

В рамках данной системы взглядов возникает попытка различить понятия «жизнь организма» (или «жизнь тела», «биологическая жизнь») и «жизнь личности». В таком случае, жизнь тела есть лишь условие для более высокого качественного уровня - для жизни личности. И если у данного человеческого организма отсутствуют определенные качества, то мы можем отказать такой жизни в моральном статусе, т.е. в отношении к ней как к человеку.

Было немало попыток дать определение тех качеств, которые могут служить критерием различия между жизнью биологической и жизнью личности. К примеру, американский биоэтик Мэри Э. Уоррен полагает, что для включения кого-либо в моральное сообщество личностей необходимы такие атрибуты, как сознание, разум, самостоятельная активность, самосознание и способность к общению [3].

Но как мы смогли бы точно провести грань между личностью и «просто организмом»? В ходе дискуссий выяснилось, что представления о таком «решающем критерии» - тоже крайняя точка зрения, как и концепция «медицинского витализма».

Биоэтические обсуждения показали, что такого окончательного критерия не существует и, возможно, сама постановка вопроса ошибочна. Так, сторонники концепции сакральности жизни высказывали мнение, что вопрос о качественной жизни - это проблема чисто медицинского характера; мы можем разрабатывать и использовать критерии только для определения того, где медицинская помощь может быть бесполезной или бессмысленной; но это не этические критерии, которые позволили бы нам отказать комулибо в достоинстве или уважительном отношении.

Таким образом, проблема ценности жизни остается открытой. По крайней мере, дискуссии на эту тему прояснили следующее. Оба подхода оказались крайними точками зрения, между которыми есть широкое множество суждений и представлений.

Биоэтики, которые по своим взглядам ближе к теории жизни как высшей ценности, настаивают, что с моральной точки зрения не существует «более ценных» или «менее ценных» человеческих жизней, что мы не можем отказать кому-либо в достоинстве или праве на жизнь; что защита жизни, насколько это в наших силах, остается важнейшей моральной обязанностью. Кроме того, они, как правило, последовательно выступают против абортов, исследований на эмбрионах, эвтаназии, экспериментов на человеческом геноме и Т.П.

Специалисты по биоэтике, которые ближе к теории «качественной жизни», со своей стороны, тоже должны быть правильно поняты. Конечно, эта теория может быть доведена до такой крайней степени, которая создаст недопустимую дискриминацию в отношении больных, престарелых, эмбрионов и т.п. Эти опасности довольно очевидны. Но разумный смысл ее состоит в том, чтобы удержать общество от злоупотреблений теорией жизни как высшей ценности, обосновать некие разумные пределы для того, чтобы медицина не тратила силы и средства там, где это не имеет смысла, высвобождая тем самым возможности помогать нуждающимся людям (учитывая всеобщую ограниченность ресурсов).

Общий вывод состоит в том, что каждая человеческая жизнь представляет собой безусловную ценность (в том числе еще нерождённого человека или человека с тяжелой патологией и т.п.); любая человеческая жизнь имеет право на достоинство и уважительное отношение. Принцип уважения человеческой жизни был и остается одним из фундаментальных требований медицинской этики. Моральная обязанность медицины стремиться сберечь, сохранить и поддержать каждую человеческую жизнь, насколько это в ее силах и оправдано совокупностью конкретных обстоятельств. 
1. The WHOQOL Group. The World Health Organization Quality of Life Assessment (WHOQOL): position paper from the World Health Organization.// Social science and medicine. - 1995. - v. 41. - Pp. 1403 - 1409.

2. Новик А.А., Ионова Т.И., Кайнд П. Концепция исследования качества жизни в медицине. - СПб, ЭЛБИ, 1999.

3. Warren M.A. On the Moral and Legal Status of Abortion // Biomedical Ethics, 5th edition, ed. T A. Mappes, D. Degrazia. New York: McGraw-Hill, 2001 - pp. 457-458.

\section{Ушаков Е.В.}

Проблема справедливости в здравоохранении: поиск идей, моделей, решений

Российская академия народного хозяйства и государственной службы при Президенте РФ (Северо-западный институт управления) (Россия, Санкт-Петербург)

doi: 10.18411/trnio-09-2021-106

\section{Аннотация}

В статье рассматриваются текущие модели медицинской помощи с точки зрения достижения справедливости. К сожалению, эти системы организации здравоохранения далеки от совершенства. В статье делается вывод о том, что идеальная система здравоохранения в принципе невозможна по ряду причин, однако реализация более справедливого состояния медицинской помощи может быть достигнута путем создания комбинированных моделей.

Ключевые слова: организация здравоохранения, справедливость медицинской помощи, биомедицинская этика, этика организации здравоохранения, моральные проблемы современного здравоохранения.

\section{Abstract}

The article examines current models of care from an equity perspective. Unfortunately, these healthcare organization systems are far from perfect. The article concludes that an ideal health care system is, in principle, impossible for a number of reasons, and the implementation of a more equitable state of health care can be achieved by creating combined models.

Keywords: healthcare organization, equity of healthcare, biomedical ethics, healthcare organization ethics, moral problems of modern healthcare.

Одна из обязательных задач государства - обеспечение граждан медицинской помощью. Для этого государство создает ту или иную систему организации здравоохранения. При этом вопросы справедливости, равенства, доступности, а также качества медицинской помощи имеют первостепенное значение. Среди основных системных механизмов предоставления медицинской помощи можно назвать такие, как частная медицина, рынок частного медицинского страхования, обязательное медицинское страхование и государственную медицину.

Каждая из этих систем имеет свои достоинства и недостатки с социетальной точки зрения. И при этом ни одна из них не решает приемлемым образом задачу справедливого обеспечения охраны здоровья и предоставления медицинской помощи. В этой связи во всех странах мира идет поиск моделей организации здравоохранения, который во многом имеет политизированный и идеологизированный характер.

Так, либертарианцы считают свободный рынок наилучшим способом регуляции медицинской деятельности, предполагая, что этот механизм даёт максимальную свободу и самостоятельность принятия решений как системе здравоохранения, так и населению. Идею свободного рынка в медицине в высшей степени реализует система частной медицины. Государство в таких условиях лишь осуществляет общий контроль за медицинской деятельностью. 